\title{
Leadership With a Purpose: Responding to Crises Through Culturally Responsive District Leadership
}

Journal of Family Diversity in Education, 2021/2022 Vol. 4, No. 2, pp. 115-129

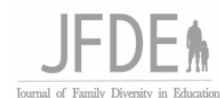

\section{Coy Carter, Jr.}

University of Minnesota, Twin Cities

Eskender A. Yousuf

University of Minnesota, Twin Cities

\author{
Bodunrin O. Banwo \\ University of Massachusetts, Boston
}

\section{Muhammad Khalifa}

The Obio State University

\begin{abstract}
This article explores how leaders in two public school districts intentionally shape their school's organizational culture to challenge harmful social ideologies and culture. The exanimation of systematic district leadership or Culturally Responsive District Leaders featured in this article demonstrates the importance of intentional, consistent, and long-lasting relational engagement of minoritized communities as an opportunity to prepare formal systems for crises of disruption. Moreover, the two district case studies featured will demonstrate the importance of systematic actors in preparing systems, like schools, to be resilient, sensitive, and accountable when complex and diverse incidents systematically construct disparate realities for their organization members. Likewise, this article explores a new concept, entitled "Organizational Stress Tests," a process that entrepreneurially builds upon past organizational incidences to function under severe or unexpected pressure.
\end{abstract}

Keywords: culturally responsive, equity, organization leadership, race, K-12 education

Over the years, educational leaders have become increasingly aware of how cultural responsiveness leadership (CRL) practices build systems that not only celebrate our students' cultures and heritages but act as dynamic tools for their socialization into a multicultural and multiethnic country. However,

Corresponding Author:

Coy Carter, Jr., Ph.D. Candidate, University of Minnesota, Twin Cities. 206 Burton Hall, 178 Pillsbury Drive SE, Minneapolis, MN 55455

Email: cart0441@umn.edu 
despite CRL's increasing popularity at the district level, some leaders fail to grapple with how harmful social ideologies and culture enter into their formal system, and they often fail to define how their marginalized students experience its cultural productions (Demerath, 2000; Piert, 2015; Wilderson III, 2014). Watkins (2001) and Apple (2004) regard the concealment and underestimation of ideology as our society's failing to see or care about how notions such as "social constructionism" are operationalized as apparatuses to control weaker members of our community. Watkins uniquely identifies this concealment as the machinery by which our society's dominant members reproduce and influence the social roles and expectations we see materializing daily at the district level (Berger and Luckmann, 1967; Watkins, 2001).

Although the machinery of social constructionism is an essential concept for this article, we regard leaders who recognize the beneficial nature of confronting social conventions such as race, creed, and gender differences as seeing entrepreneurial opportunities to disrupt. Moreover, we regard these leaders as building the sociocultural system power and experience needed to challenge organizational inertia (Gilbert, 2005). The educational leaders featured in this article demonstrate the importance of intentional, consistent, and long-lasting relational engagement with communities to prepare for and manage crises such as COVID-19 and the social challenges that follow. The featured district leaders recognize that their focus on engagement is a process of forward-thinking capacity building that intentionally prepares their organization for resiliency. This is especially important when complex and diverse incidents from "a failed COVID response to the rise of white nationalism" systematically construct disparate realities for members of their organization. Drawing on Culturally Responsive Leadership (CRL) as the theoretical framework to analyze district leaders' responses, this article builds on the previous work of Culturally Responsive School Leadership (CRSL) and uses two case studies as examples of what authentic Culturally Responsive District Leaders (CRDL) should look like when CRL is systematically integrated into practice.

This article is shaped around two questions that examine how school district leaders respond and adjust to crises and conflicts driven by changing community demographics. The first question explores how school leaders develop their school culture through existing relationships with marginalized communities to manage organizational crises. The second question examines how school leaders without prior relationships to families and communities respond to racial incidents, conflicts, and injustices. This article contributes to the literature on school leadership by investigating how two school leaders-one from Pogonia Hills and one from Dakota Public Schools (DPS)_build institutional CRL capacity through intentional and critical self-reflective practices designed to disrupt negative notions of marginalization. In these two case studies, we systematically examine how harmful social attitudes shaped by social differences, histories, and stereotypes are repaired and excised out of the formal system by two organizational leaders we describe as CRDLs.

The first case study from DPS examines Jessica Dawson's 30-year history of intentional CRL practice. We focus on how she infuses practices of equity and cultural responsiveness into every aspect of her district, transforming how students, teachers, and leaders understand inclusion and cultural differences. The second case study explores Pogonia Hills Public Schools' novice district leader in the early stages of CRL implementation. In this case study, Karen Williams demonstrates how the beginning stages of culturally responsive leadership shift the organizational trajectory toward critical reflection patterns that uncompromisingly examine how culture and race influence student experiences and engagement. Although both cases are examples of CRDL, both leaders are in different phases of CRL and require a leadership praxis that is responsive to a particular time and space. 


\section{Journal of Family Diversity in Education}

\section{Literature Review}

\section{Understanding Organizational Impacts/Influences}

In recent decades, sociologists have examined how complex organizations are influenced and affected by race and racial histories. Stinchcombe's (1965) classic paper "Social Structure and Organizations" argues that organizational formation is influenced by external environmental forces that persist long after an organization's foundation. Furthermore, Stinchcombe describes the process of imprinting, the idea that the past influences the present, and highlights how organizations are defined and affected by their foundation. If organizational leaders seek to eliminate histories of negative imprinting, they need to purposely work within organizations to identify and repair histories of harm (Marquis \& Tilcsik, 2017).

Although Stinchcombe primarily focuses on the industrial level of organizations, he nevertheless offers a lens for seeing how traditions of white supremacy and social domination are embedded into formal organizational cultures and passed down through the multiple cycles of organizational participants. Similarly, March (1991) views organizational learning, particularly technical features such as the "usage of Best Practices and memo-ing," as a way for organizations to learn from past mistakes. In other words, organizations should preserve cultural cues that can inform future members of the organization by sending information to them across time. For March, this transforms the organization into a living breathing object, capable of remembering and learning through multiple cycles of participants (Groysberg, Lee, Price, \& Cheng, 2018).

\section{Culturally Responsive Leadership}

Scholars of CRL regard their approach to school leadership as a process of influencing and expanding the school's cultural context by addressing all students, parents, and teachers' cultural needs. For example, Khalifa (2019) observes culturally responsive school leadership as a beginning stages of critical reflection tasks that promote an inclusive and open school culture. The goal is that marginalized students would understand, recognize, and find safety within this culture. Moreover, he imagines these leadership vanguards as having an active and connective presence with the community members they serve. In other words, a culturally responsive leader is a forward-thinking person who understands that organizations and power continuously shift and change over time. This requires a strong leadership disposition and awareness of school and social contexts, particularly when responding to the needs that accompany cultural and social shifts (Khalifa, Gooden, \& Davis, 2016; Shields, 2019).

From a structural perspective, CRL is a necessary tool to respond to our nation's diversifying schools. For the first time in US history, public schools now serve more non-white students than white students. Even as this demographic reality begins to inform the field of education, teachers remain predominantly white women, and the leaders are mainly white men. Some argue that these leaders lack the capacity to initiate the dynamic processes needed to interrogate and repair discourses surrounding race and diversifying communities. This is evident in the lack of disruption and the perpetuating of or acquiescing to deficit discourses and systems in mainstream schools that harm minoritize students through organizational reproduction. This is observed in discussion of the "opportunity/academic gap". Marginalized students are more often identified as having special education learning needs that are disassociated from academic metrics and instead tied to subjective interpretations of student behavior (Cortina, 2008; Eitle, 2016). They are disproportionately disciplined when violating the white, middle-class norms of colonial school culture. In turn, they receive more suspensions and office referrals than their white peers (Irby, 2014; Nowicki, 2018; Vavrus \& Cole, 2002). This excludes them from classroom instruction which impacts the learning time and 
teachers' and leaders' attention further contributing to being stigmatized as less academically successful than their white peers. Instead of addressing the systemic reproduction of racism and racial harm, school leaders continue to discuss an "unexplained" or "unaccounted for" gap in academic progress. As a result, a framework capable of engaging issue of diversity like is required (Young, Madsen, J., \& Young, M. A. (2010)).

One of the most significant objectives for culturally responsive school leaders is to humanize minority youth both in and out of school. Culturally responsive leadership relies heavily on school leaders, as it is connected to their (anti-oppressive and culturally responsive) disposition and their ability to lead organizational change. More specifically, CRL must promote school climates that embrace minority youth and their identities. Scholars such as Banwo (2020) suggest the intentional implementation and promotion of culturally responsive pedagogies and organizational practices that establish communicable relationships with school officials, parents, and community members. Indeed, Khalifa (2018) believes that a leader must not only be critically self-aware but ready to employ administrative machinery to act on the information gleaned from "dual communicable relationships." While critical reflection is a crucial tenant of CRL, one must also show an understanding of one's biases and a willingness to use the organization's machinery to confront detrimental ways of viewing minority students through deficit framing and narratives.

\section{Parent and Cultural Liaisons}

One way that districts are creating culturally responsive and inclusive spaces for marginalized students is by tapping into their communities and hiring cultural liaisons (Howland, Anderson, Smiley, \& Abbott, 2006). Cultural liaisons provide a community/cultural-centric knowledge and understanding that has long been excluded from formal school environments. They help bridge the gap for schools to confront the historical oppressions and language barriers that impact student learning and outcomes (Colombo et al., 2006; Villa, Thousand, Meyers, \& Nevin, 1996). Different scholars also identify the role of cultural liaisons as a cultural broker (Weiss \& Cambone, 1994) or buffer who serves as a "translator and a transmitter (Smiley, Howland, \& Anderson, 2008, p. 342). As cultural liaisons are relatively new roles in schools, particularly in the US, the expectations and job descriptions for them remain unclear. A cultural liaison can be a parent, teacher aid, a community member, (Howland, Anderson, Smiley, \& Abbott, 2006; Martinez-Cosio \& Iannacone, 2007) or someone who is specifically hired to be a liaison.

The literature addressing the roles, expectations, and even locations (e.g., school level, district level, or contractor) of cultural liaisons is limited. However, previous studies have shown how cultural liaisons must be placed in a leadership role-formal or informal — to be able to enact notable change (House \& Hayes, 2002; Nolan \& Palazzolo, 2011). This is important to consider when identifying a leader's commitment, as only having/hiring a cultural liaison is different from placing them in a position of power or allowing them to meaningfully contribute to the desired and/or necessary changes. Cultural liaisons are also advocates for marginalized students. Martinez-Cosio and Iannacone (2007) discuss parent liaisons who can learn and navigate the unwritten and inaccessible rules to accessing adequate resources and make other demands to help their children. We argue that these qualities also apply to any cultural liaison, as many students do not have parent liaisons/advocates who are available to show up in classrooms or school spaces because they experience exclusion or have other responsibilities/priorities.

Having access to hidden processes and procedures that traditionally benefit well-served students and being able to share these "rules" with marginalized families allows a cultural liaison to become a potential advocate within the school. Lastly, cultural liaisons provide a shared cultural and community connection that a teacher or administrator cannot provide. Lane (2017) highlights the example of a 


\section{Journal of Family Diversity in Education}

teacher aide who, unlike teachers, can visualize and verbalize hidden procedures and practices for marginalized students and their families. Cultural liaisons can serve as conduits of clarity for marginalized communities (Martinez-Cosio, \& Iannacone, 2007).

\section{Theoretical Perspective: Culturally Responsive School Leadership}

According to Khalifa (2018), leaders must promote schools that embrace the identities of minoritized youth, implement and promote culturally responsive pedagogy, and establish culturally responsive relationships with parents and community members. Khalifa (2018) argues that a leader's critical self-reflection recognizes both the history of marginalization of oppressed groups and the role leaders play in reproducing or contesting oppressive contexts. Leaders bear a unique responsibility for explicitly articulating how a school's organization will center students' concerns, particularly regarding cultural productions such as the inclusion and acceptance of minority students (Asante, 1991). The following four behaviors provide opportunities for promoting cultural responsiveness within a school:

1. Critical self-awareness focuses on the need to interrogate the ways that both leaders and their organizations contribute to, reproduce, or contest oppressive practices in schools (Gooden, 2005, McKenzie et al., 2008).

2. Culturally responsive curricula and teacher development require responsive leaders to support new curriculum and instruction modes that improve learning for and humanize minority students (Khalifa, 2018). This includes accessing community assets and experiential knowledge and ensuring their inclusion.

3. Culturally responsive and inclusive school environments address school climates and spaces and how they influence disparities in educational outcomes. Environments that affirm students' identities are critical, and school leaders should be able to leverage resources that foster embedded cultural affirmation (Dantley and Tillman, 2006, Riehl, 2000).

4. Engaging students and parents in community contexts incorporates adults outside the school as bearers of culturally appropriate knowledge. Thus, leaders establish routines for learning from the community and advocating for community knowledge, self-determination, and goals. This leads to a more culturally responsive education (Ishimaru, 2018) while also highlighting the place-based focus of CRSL.

\section{Methodology}

Our inquiry used a multi-year (September 2016-March 2020) qualitative case study research design that involves both embedded observations and interviews with district and school administrators, teachers, students, and community members. The qualitative research approach is established based on the premise that organizational cultures, practices, and realities are socially constructed, complicated, and in constant motion. Our approach was guided by an interpretative and descriptive approach to social phenomena, particularly the meaning that people use to understand their world and their reality. In particular, we focus on how participants' personal racialized experiences, through knowledge and understanding of history or personal perceptions, are used as an organizational “meaning-making" device for social analysis (Croker, 2009; Elliott \& Timulak, 2005). 
We performed data analysis using a content analysis method. During the analysis, we developed sub-themes and interpreted them for each of the conceptual areas. The interviews were conducted during the years 2016-2020. The first and second authors administered the interviews. The interviews were digitally audio-recorded and transcribed for analysis purposes by the transcription service REV.com and Zoom Video Communications, Inc. audio transcription.

This study is part of two larger culturally responsive school leadership projects that sought to investigate how district leaders in majority white and minority school districts perceive and act upon social, gender, class, and ethnic differences. The first data source is a series of 60 in-depth interviews conducted over five years. The second data source is broken into two parts. The first part refers to data gathered from district-level student and teacher focus groups. The district recommended the focus group participants. The second part refers to information gathered from two years of youth-led participatory action research (YPAR) in both featured school districts.

\section{Research Questions}

1. In what ways are educational leaders who enjoy existing relationships with their school communities better positioned to manage crises such as COVID and failed state and federal responses to the pandemic?

a. How are they positioned to manage other issues, such as the rise of white nationalism and uprisings and protests against police brutality?

2. How do school leaders without prior relationships with or access to families, community members, and groups respond to such crises and/or other racial incidents, conflicts, and injustices?

\section{Study Background and Cultural Liaisons Context}

The cultural liaison program was adopted into the Midwest state regulations for special education in 2001. As envisioned by the state, the program serves to advocate for minority families and students to ensure equitable access to school and district services. According to the regulations, a cultural liaison refers to a person who is of the same racial, cultural, socioeconomic, or linguistic background as the pupil. The liaison also meets the following criteria:

a) provides information to the school's special team about the pupil's racial, cultural, socioeconomic, and linguistic background

al education team about the pupil's racial, cultural, socioeconomic, and linguistic background;

b) assists the team in understanding how racial, cultural, socioeconomic, and linguistic factors impact educational progress; and

c) facilitates the pupil's parents' understanding and involvement in the unique education process.

Ishimaru et al. (2016) have identified the typical cultural liaison (broker) position as one of fostering the conformity of non-dominant families to the existing professional norms. In contrast, DPS and Pogonia Hills Public Schools have expanded the state's expectations and incorporated a more reciprocal and challenging perspective that emphasizes student and family voices and focuses on equity and inclusion. Jessica and Karen regard student voices as an organizational tool that needs continuous examination through the development of healthy, culturally responsive relationships. For Jessica, Karen, and their districts, attention to student and family engagement has sought to infuse equitable affirmations and cultural responsiveness into every aspect of the district's culture and administrative practices. 


\section{Journal of Family Diversity in Education}

Our case studies explore how district-level leadership enacts CRSL practices at a systemic level and transforms how organizational citizens experience and understand equity. Although Jessica and Karen regard their positions as opportunities to advocate for students and families, they also understand that their roles involve building the equity and inclusion capacity of their districts. This capacity building includes guiding teachers, students, and parents towards creating a district that fully values and respects all students' authentic cultural productions.

\section{Findings: Case Studies}

\section{Case 1: DPS - "20 years in, and I am still fighting"}

The DPS system's cultural liaison role has evolved from being a classroom helper to a professionalized position tasked with enacting significant cultural change to impact the school and its community. Over 30 years, the DPS system has developed this equity position to be somewhat distinct from other surrounding districts through their intentional focus on community connectedness. Their equity professionals have a shared cultural affinity with marginalized student populations (Weiss \& Cambone, 1994). Moreover, the district views this intentional organizational practice as one that allows senior leadership an authentic and direct pipeline to the marginalized communities they have identified for interventions.

Jessica Dawson, a veteran administrator and head of DPS's Office of Equity and Inclusion (OEI), has been the driving force behind DPS's culturally responsive work since her arrival in the district 20 years ago. Although the OEI's cultural liaison program is not her original idea, she has shaped and expanded the program into one of the most dynamic and respected cultural responsiveness programs in the state. Throughout Jessica's tenure, she has cultivated her district's equity approach through her team's care for and responsiveness towards marginalized voices. Jessica regards student voices as a critical, culturally responsive tool that needs to be continuously examined through the development of healthy, culturally responsive relationships with students.

Moreover, for Jessica and DPS, this work has sought to infuse equity and cultural responsiveness into every aspect of the district and transform how students, teachers, and leaders understand inclusion and cultural differences. We perceive DPS's work as the district seeing and acting on "negative" and "racialized" organizational experiences, which we regard as commonplace in systems that are struggling with constructing healthy, culturally responsive environments (Asante, 1991). Jessica's practice of CRDL is unique within an educational landscape that fails to regard minority students' voices as significant warning signs of a lack of responsiveness. Through everyday interpersonal and organizational interactions, students and families transmit messages about their social and emotional position in the broader system. Jessica and her district recognize that these interactions serve as social cues for her office to gauge students' and parents' experiences and expectations. Her liaisons' development of their fine-tuned insight permits them to form deep, close relationships with students and families that help them improve learning outcomes and student socialization.

\section{Listening to Social Signals}

An essential goal for Jessica's team is creating institutional communication pathways between leadership and the broader organizations through which marginalized parents and students can express concerns for needed changes. For example, Jessica recounted a story about one of her parents being so upset with her son's school that she would place a tissue in the form of a Ku Klux Klan mask on the table during her school meetings. Although the relationship had deteriorated before Jessica was involved, it concerned her that the school's leadership team could not mediate this obvious racialized situation. The mother's nonverbal signals concerned Jessica and required her to step in and resolve 
the problem. Jessica explains how she had formed a relationship with the mother's son, which allowed her to approach the mother as more of a friend: "before I had the first meeting I saw what she was wearing, and I said you go to a meeting like that... don't you have a coat outside...she went out and put on something. She came back in. She said nobody has ever said anything to me like that, but I know they were thinking it... and we laughed about that."

Jessica's breakthrough was only possible because she had worked with this family and demonstrated that she was coming from a place of sincere concern for the mother's son. The mother, according to Jessica, was not being heard or valued. Moreover, she did not have a person to trust or be honest with her. Jessica stated that "every time she threw that tissue on the table...I would swipe it off." Jessica's office focuses on capacity building and examining their district's culture, histories, and practices when it fails to be flexible and inclusive of its marginalized members. During our conversation, Jessica spoke about school leadership teams sometimes stop trying, blame external influences for their roadblocks, or assume marginalized people are reluctant to engage when students and families send social signals. Moreover, she believed these moments difficulties were times for growth and should be embraced and built upon.

\section{Culturally Responsive District Leadership}

Jessica regards social signs, one of the driving forces of DPS's equity policy, as an opportunity to act systematically to find the correct pathway for improvement. Moreover, over her tenure in the OEI, her eight-person team has cultivated relationships with students and teachers that have helped bridge the cultural gaps between families and the school district. The DPS team views this work as a crucial policy and organizational tool that effectively builds trust and the organizational capacity to overcome inevitable racialized roadblocks (i.e. organizational stress test and forward-thinking capacity building).

Moreover, Jessica and her office regard their position as "advocates" as an opportunity for the district to celebrate and strengthen students' overall schooling experience and embrace their differences. Jessica's approach is to not only improve the schooling experience for students on the ground but also increase her district's organizational capacity through the development of culturally responsive leadership skills of her district. She seeks to empower employees who "get the importance of equity" and who will one day be the leadership core of the district. For example, when we closed our interview, Jessica recounted concerns she has had with white female teachers targeting Somali male students for exclusionary discipline practices because of a pervasive belief that Muslim men do not fully respect women.

According to Jessica, when this problem was first raised as an equity concern, she had trouble explaining to the close-knit Somali community the racial and cultural nuances of the US. That they needed to be on guard for essentialist thinking from teachers and be prepared, if need be, to challenge a fight for a free and equitable education for their children. We recount this story because DPS's Somali cultural liaison was the first point of contact for Somali students at risk from teachers' essentialist thinking. Moreover, this Somali cultural liaison first brought the issue to Jessica, a senior district administrator. This liaison also was the first one to investigate, advocate, and make steps to disrupt the essentialist attitudes that the students and families found harmful.

Due to their socialization, the teachers from Jessica's story brought their racism and essentialist ideas about Somali, black, and Muslim students into DPS. Furthermore, this initially unchallenged view of students by school staff served to intentionally construct a malicious and harmful social reality. Without Jessica and her team's strong relationships with minority families, this issue would have likely continued unabated.

While the teachers' behavior was undoubtedly damaging to the black and Muslim students in the schools, this issue also relates to deeper concerns. The teachers denied the students an opportunity to be a part of the broader community as their authentic cultural selves. Moreover, for DPS's equity 


\section{Journal of Family Diversity in Education}

agenda, these practices served as a reminder of how far their district has come and how far they must still go. Jessica stated that:

I'm relational. I build relationships with people, and my heart is really with kids. It really is because I know what it feels like to be sad. I know what it is like to be different, to be called ugly, be called white when you are not, and be teased about your freckles...I have gotten to a point where I tell kids that, yes, it used to hurt, but guess what, it's all me.

\section{Case 2: New Leadership, New Beginnings and a New Shift towards Responsiveness}

As Karen Williams transitioned into her new position, she quickly recognized her district's lack of preparedness in connecting and creating healthy spaces for marginalized students and their families. Before moving to her new role as the "principal on assignment for equity improvement," Karen served three years in the district. This allowed her to become familiar with the gap in achievement and opportunity that separates marginalized students and their white peers. Consequently, in this new position, she was not surprised to hear about the pervasive practices of over-policing, stereotypes, and racialization of Black and brown students. Pogonia Hills is known for its demographics in a way that even the city's nickname refers to both its foundation as a majority white population and unique topographical features. However, as the district became more diverse due to school choice options and an influx of minority families, Pogonia Hills began experiencing a community and racial crisis fueled by antiblackness and pervasive exclusionary practices.

As Karen began to settle into her new position, she recognized how pivotal the changing demographics were in how Pogonia Hills approached gaps in student engagement. According to Karen, the structural translation from historically serving white middle class and affluent students to merely accounting for and welcoming marginalized students' as new residents and community members had not happened. Her training in CRSL practices allowed her to be critically self-reflective in assisting the district's treatment of and relationships with its growing marginalized student population

\section{Equity Audits as a Critical Reflection on Organizational Failure}

A significant component of equity audits is to elevate students' voices by focusing on their experiences and lived realities. Karen believed that it was paramount to share how the students understood racialized events in the district. Moreover, she also saw the process of equity audits as an opportunity for the leadership to begin seeing how a lack of organizational inclusion and cultural responsiveness seriously harmed their students. Although many of the findings were deeply disturbing, it was clear that the district had little to no relationships with existing minority students and their families.

Marginalized students in the district voiced that they could not be their authentic selves in their schools and classrooms. Additionally, students reported being chastised and bullied by their white peers when expressing their traditional and cultural practices. However, Karen was most disturbed by teachers and administrators simply ignoring racialized slurs and the inappropriate touching of other students. As a result of this negligence, students-Black students in particular-were forced to learn in an environment where white students could get away with racism. At times, white students would employ something identified as "the N-word pass"-fabricated permission by an unknown Black student to say the word "nigga" or "nigger" without consequence. Karen found that this practice deeply demoralized some students and challenged their ability to learn in a fair and healthy school environment.

Although marginalized students were visible in the disproportionate discrimination and discipline they faced, they were invisible in the school curriculum and epistemologies discussed in the classroom. This was most relevant for Indigenous students who felt erased by the colonial curriculum. 
One student noted, 'You don't hear about any Natives. Like, what happened to them? They don't teach it at all. Natives are only mentioned in passing." In addition, when striving for high academic achievement, marginalized students were cast as unintelligible by teachers and administrators. One student accounted the following:

I took an honor class...I walked in there first day and it was all white...I felt really uncomfortable... one day the teacher came up to me and said, "I don't think this is right class for you." I said, what do you mean? He said, "take a look around." and I said, they are all white, and he said, "exactly"...he like installed a fear in me of having to do better that has impacted me all throughout my education career.

\section{Moving to Culturally Responsive District Leadership}

In an interview with the local press, Karen indicated the need to change and the district's willingness to make that change a reality. She began to create and repair the relationship between the district and marginalized families through CRSL. This involves engaging with critical consciousness and naming the oppressive practices that the district is enacting upon marginalized students. Karen has further advanced the district by creating an equity and engagement director position and embedding that position within the senior levels of district leadership. Moreover, she intentionally shaped the position in contrast to surrounding districts by targeting students and parents' engagement in a community context. This approach meets them where they are instead of forcing interaction on hostile foreign ground.

Although Pogonia Hills is only beginning its equity journey, its organizational embrace of culturally responsive leadership serves as a tool to disrupt the machinery of harm that pervasively defines marginalized student experiences. For more than two years, we have known Karen and watched her support student development through practices such as equity audits, YPAR, and direct outreach to marginalized communities. Moreover, we have seen Karen use these organizational tools as an opportunity to challenge stagnate, outdated thinking within her district. While there is still considerable work to be completed, we can see how the groundwork is being laid for both the academic and social-emotional success of all students.

\section{Discussion}

In the case study examples, we see differential degrees of effectiveness in response to racialized incidents. Since Jessica and her team have demonstrated their continued commitment to marginalized communities and families over many years, they are better positioned to bridge the gaps between families and the school district. In comparison, Pogonia Hills Schools are still in the beginning of their journey. This difference is significant. We argue that schools with CRDLs can better respond to racial incidents, crises, conflicts, and injustices than schools without these leaders. The relationships cultivated by the CRDLs establish communication pathways with school leaders who may not have prior relationships with or access to these families and communities.

Similarly, we claim that the overall effectiveness of the response to these issues is due to organizational stress tests. Similar to an economic stress test, an organizational stress test reveals issues within the organizational structure. These stress tests encourage the organization to grow stronger and enhance its abilities to weather future crises and incidences. Therefore, the more frequently an organization has responded to racialized incidents and injustices, the more effective their organizational players' capacity will be to function under severe or unexpected pressure. Ray (2019) understands this by examining what he terms the racialized organization and its ability to mobilize social phenomena, such as mobilizing whiteness as an organizational credential or access point for dominant organizational members. 


\section{Journal of Family Diversity in Education}

However, Khalifa (2018) suggests that system leaders such as Jessica and Karen are positioned within their organizations as system-wide CDRLs who push and pull their districts towards an organizationally-reflective view of marginalized members' conditions and lived experiences. In both cases, leaders practicing CRL through critical self-reflection intentionally shaped and drove their organization to strengthen their marginalized students' social and organizational experience.

\section{Culturally Responsive School District Leadership (CRSDL)}

The DPS Director of Equity and Inclusion, Jessica, has demonstrated her long-standing commitment and ability to develop authentic relationships with minority students and their communities. Through her attentiveness to social cues, Jessica and her team captured these communities' concerns and communicated them to school leadership. Jessica then leveraged her position to facilitate institutional communication pathways between school leadership and marginalized communities and students. It is important to note that Jessica and her team received hostile responses from school workers when they attempted to shift the culture or report incidences that they believed were harmful to minority students. According to Jessica, teachers complained that her team implemented additional bureaucratic layers as a tool to undermine their siloed classroom space. While Jessica expressed her understanding of the teachers' position, she encouraged her liaisons to form a strong working relationship with school leadership, which she felt would translate to a positive relationship with teachers and other staff members.

In contrast, Karen's history of CRL demonstrates how district leaders can grapple with negative minority experiences and histories. Through critical self-awareness, Karen exhibited how leaders can alter their system's trajectory towards a process of culturally responsive organizational change. At the beginning of Karen's CRSL work, the district's values, beliefs, and dispositions did not healthily and responsively serve marginalized students. Karen changed this with her leadership training, as she instituted a process of repeatedly questioning systematic practices and attitudes through critical consciousness. This served to begin a process that would disrupt her district's oppressive practices and culture. Her leadership team began developing the district's strategic vision for the anticipated multiethnic and multicultural district they were becoming.

\section{Organizational Stress Test}

Both leaders argue that leadership development should focus on a process of forward-thinking capacity building that intentionally prepares their organizations to be resilient when racialized incidents occur. For Karen, her reflection on her district's neglect to recognize the significance of culture and racism, principally how it influenced their organizational structures, served as a powerful example of how deliberate processes hurt students by not challenging power and organizational inertia. Her CSL training led her to understand that organizations have agents within them who produce operations of interrelated processes, actions, and meanings that result in practices that maintain social inequalities (Acker, 2006).

Khalifa (2018) regards the disruptions of these operations as a critical juncture that leaders must examine when developing CRL to create a long-lasting and responsive institutional foundation. Both Jessica and Karen understand their roles as unmasking the structural machinery of whiteness, which is the residue of an earlier incarnation of their district's culture and practices. For Jessica, she unmasked this issue through her attention to marginalized students' social signals and how they serve to identify organizational blind spots. Jessica's critical work requires her to situate herself between teachers and staff who may not be ready for a changing organization and students and families harmed by a lack of organizational equity. Jessica's office carefully navigates and tailors its organizational goals of pushing and pulling actors towards a lasting and responsive foundation. 
Moreover, we regard Karen and Jessica's work as contributing to an organizational stress testthrough their leadership work that uses systematic breakdowns and activities (i.e. racial, equity and social differences) to prepare the organization's power and capacity to learn from mistakes and move forward within the new organizational paradigm. Moreover, we regard Karen and Jessica's ability to recognize, metabolize, and move forward with the new knowledge learned from the organizational breakdown as also preparing their school system to function better under severe or unexpected pressure. By laying the systematic groundwork of CRL, both leaders have strategically prepared actors within the district to grapple with future organizational crises. Indeed, both featured leaders understand their structural improvement mission is grounded in equity notions that center on aligning new policies, procedures, and equity values (Ladson-Billings, 1995). Moreover, their practices of establishing trust with white educators allow them to embrace the histories and raw experiences of their students while simultaneously moving their practice and leadership into a critically reflective and responsive framework. This space of criticality has the effect of authentically building social capital that is key to benefiting all students.

\section{Culturally Responsive District Leader Effectiveness}

The two CRDL cases demonstrate how these leaders have responded to the challenges of racialized incidents and other crises. We argue that organizational stress tests explain the effectiveness of their responses. By highlighting both cases, we aim to illustrate that CRL is an intentional practice that requires collaboration with minority communities and families, attentive listening, strategic thinking, and a willingness to advocate for change. These instances demonstrate how district leaders can employ CSL practices to create equitable solutions to racialized incidents within their school districts.

These actions also illustrate two critical components of CRDL: 1) systematically centering the concerns and voices of minoritized students and communities; and 2) communicating these concerns with school leadership to advocate for and promote dynamic systemic action for school improvement. This concept goes beyond the localized school building to the systemic leadership level and leaders who have a complete view of the systems' workings and operations. In the business field, this level of leadership is designated as "C-suite leadership." Moreover, these featured change agents demonstrate how district leaders can employ culturally responsive practices across systems to create equitable solutions to racialized incidents within their school districts. Indeed, we see these leaders as establishing synergistic communication pathways (two-way communication pathways) between minoritized communities, families, and school leaders, that enables school districts to be more responsive to different issues and concerns that fell into what scholars like Banwo (2020), term leader's cultural blind spots.

\section{Implication for Practice}

As district leaders attempt to implement positive changes, they must rely on relationships with the community if they hope to establish and promote culturally responsive organizations. In this research project, community relationships allowed district-level leaders to leverage community knowledge in ways that infused cultural responsiveness throughout different programs and structures. This phenomenon has deep implications for school leadership practice, as it explicitly calls on district leaders to institutionalize practices and policies. At a broad level, this research suggests that a cadre and network of cultural workers are needed to establish relationships and shift institutional practices.

These cultural liaisons must reflect the backgrounds of minority students. Due to the reproductive nature of white supremacist thinking, which is prevalent throughout a number of school structures, some cultural workers also need to examine and address white social and racial framings. Finally, leadership practices must always be critically self-reflective to allow educators to learn how to make 


\section{Journal of Family Diversity in Education}

schools more inclusive. Awareness of practices of oppression that are automatically reproduced must be highlighted by elevating community perspectives and voices. Equity audits, community listening forums, frequent trips to the communities in service, and culturally responsive school leadership training are all strategies that can be undertaken to improve education for minority students.

\section{References}

Acker, J. (2006). Inequality Regimes Gender, Class, and Race in Organizations. Gender and Society, Vol. 20, No. 4, pp. 441-464.

Apple, M. W. (2004). Ideology and Curriculum. Milton Park, Abingdon, Oxfordshire: Routledge Publishing.

Asante, M. K. (1991). The Afrocentric idea in education. The journal of negro education, 60(2), 170-180.

Banwo, B. (2020). African Communitarianism as Black Student Motivation: An Institutional Exploration of Collectivism in African-Centered Education (Unpublished doctoral dissertation). Minneapolis, MN: University of Minnesota. Retrieved from University of Minnesota.

Berger, P. L., \& Luckmann, T. (1967). The Social Construction of Reality: A Treatise in the Sociology of Knowledge. New York: Anchor Books.

Colombo, M. G., Grilli, L., \& Piva, E. (2006). In Search of Complementary Assets: The Determinants of Alliance Formation of High-Tech Start-Ups. Research Policy, 1166- 1199.

Cortina, L. M. (2008). Unseen Injustice: Incivility as Modern Discrimination in Organizations. Academy of Management Review.

Croker, R. (2009). Qualitative Research in Applied Linguistics: A Practical Introduction. London: Palgrave Macmillan.

Dantley, M. E., \& Tillman, L. C. (2006). Social justice and moral transformative leadership. Leadership for social justice: Making revolutions in education, 16-30. Boston, MA: Allyn \& Bacon.

Demerath, P. (2000). The Social Cost of Acting "Extra": Students' Moral Judgments of Self, Social Relations, and Academic Success in Papua New Guinea. American Journal of Education, 196-235.

Eitle, T. M. (2016). Special Education or Racial Segregation: Understanding Variation in the Representation of Black Students in Educable Mentally Handicapped Programs. The Sociological Quarterly, 575-605.

Elliott, R., \& Timulak, L. (2005). Descriptive and interpretive approaches to qualitative research. In J. Miles, \& P. Gilbert, $A$ bandbook of research methods for clinical and health psychology (pp. 147- 159). Oxford: Oxford University Press.

Groysberg, B., Lee, J., Price, J., \& Cheng, J.-J. (January-February 2018). The Leader's guide to corporate culture. Harvard Business Review.

Gooden, M. A. (2005). The role of an African American principal in an urban information technology high school. Educational Administration Quarterly, 41, 630-650. doi:10.1177/0013161X04274273

House, R. M., \& Hayes, R. L. (2002). School Counselors: Becoming Key Players in School Reform. Professional School Counseling.

Howland, A., Anderson, J. A., Smiley, A. D., \& Abbott, D. J. (2006). School Liaisons: Bridging the Gap between Home and School. School Community Journal, 47- 68.

Irby, D. J. (2014). Revealing Racial Purity Ideology: Fear of Black-White Intimacy as a Framework for Understanding School Discipline in Post-Brown Schools. Educational Administration Quarterly, 50(5), 783-795. https://doi.org/10.1177/0013161X14549958

Ishimaru, A. M., Torres, K. E., Salvador, J. E., Lott, J., Williams, D. M. C., \& Tran, C. (2016). Reinforcing deficit, journeying toward equity: Cultural brokering in family engagement initiatives. American Educational Research Journal, 53(4), 850-882. 
Khalifa, M. (2018). Culturally Responsive School Leadership. Cambridge: Harvard Education Press.

Khalifa, M. A., Gooden, M. A., \& Davis, J. E. (2016). Culturally Responsive School Leadership. Review of Educational Research, 1272-1311. Retrieved from https://experts.umn.edu/en/publications/culturally-responsive-school-leadership-a-synthesisof-the-litera

Ladson-Billings, G. (1995). Toward a Theory of Culturally Relevant Pedagogy. American Educational Research Journall, Vol. 32, No. 3. (Autumn, 1995), pp. 465-491.

Lane, K. L. (2017). Building Strong Partnerships: Responsible Inquiry to Learn and Grow Together: TECBD-CCBD Keynote Address. Education and Treatment of Children, 57- 618.

March, J. G. ( January 1991). Exploration and Exploitation in Organizational Learning. Organization Science, p71-87.

Marquis, C., \& Tilcsik, A. (2017). Imprinting: Toward a Multilevel Theory. Academy of Management Annals.

Martinez-Cosio, M., \& Iannacone, R. M. (2007). The Tenuous Role of Institutional Agents: Parent Liaisons as Cultural Brokers. Education and Urban Society. Volume: 39 issue: 3, 349-369.

McKenzie, K. B., Christman, D. E., Hernandez, F., Fierro, E., Capper, C. A., Dantley, M., . . . Scheurich, J. J. (2008). From the field: A proposal for educating leaders for social justice. Educational Administration Quarterly, 44, 111-138. doi:10.1177/0013161X07309470

Martinez-Cosio, M., \& Iannacone, R. M. (2007). The Tenuous Role of Institutional Agents: Parent Liaisons as Cultural Brokers. Volume: 39 issue: 3, Volume: 39 issue: 3. Education and Urban Society, 349-369.

Nolan, B., \& Palazzolo, L. (2011). New Teacher Perceptions of the "Teacher Leader" Movement. NASSP Bulletin. v95 n4, 302- 318.

Nowicki, J. M. (2018). K-12 Education: Discipline Disparities for Black Students, Boys, and Students with Disabilities. Report to Congressional Requesters. Washington, DC: US Government Accountability Office. Retrieved from https:// files.eric.ed.gov/fulltext/ED590845.pdf

Piert, J. (2015). Alchemy of the Soul: An African-centered Education (Black Studies and Critical Thinking). New York: Peter Lang Inc., International Academic Publishers.

Ray, V. (2019). A theory of racialized organizations. American Sociological Review, 84(1), 26-53.

Riehl, C. J. (2000). The principal's role in creating inclusive schools for diverse students: A review of normative, empirical, and critical literature on the practice of educational administration. Review of Educational Research, 70, 55-81.doi:10.3102/00346543070001055.

Shields, C. M. (2019). Becoming a Transformative Leader: A Guide to Creating Equitable Schools (Eye on Education). London: Routledge \& CRC Press.

Smiley, A. D., Howland, A. A., \& Anderson, J. A. (2008). Cultural Brokering as a Core Practice of a Special Education Parent Liaison Program in a Large Urban School District. Journal of Urban Learning, Teaching, and Research. v4, 86- 95.

Stinchcombe, A. (1965). Social Structure and Organizations. Handbook of Organtzatlons, 142-193.

Vavrus, F., \& Cole, K. (2002). "I didn't do nothin” ': The discursive construction of school suspension. The Urban Review, 87- 111.

Villa, R. A., Thousand, J. S., Meyers, H., \& Nevin, A. (1996). Teacher and Administrator Perceptions of Heterogeneous Education. Exceptional Children, 29- 45.

Watkins, W. H. (2001). The White Architects of Black Education: Ideology and Power in America, 1865-1954. New York: Teachers College Press.

Weiss, C. H., \& Cambone, J. (1994). Principals, Shared Decision Making, and School Reform. Educational Evaluation and Policy Analysis. 16(3), 287-301. 


\section{Journal of Family Diversity in Education}

Wilderson III, F. B. (2014, 10). "We're trying to destroy the world" Anti-Blackness \& Police Violence After Ferguson. (J. Ball, T. S. Burroughs, \& D. Hate, Interviewers) Retrieved from http://sfbayanarchists.org/wp-content/uploads/2015/01/frank-b-wilderson-iii-were-trying-to-destroy-theworld-antiblackness-police-violence-after-ferguson.pdf

Young, B. L., Madsen, J., \& Young, M. A. (2010). Implementing diversity plans: Principals' perception of their ability to address diversity in their schools. NASSP Bulletin, 94, 135-157. doi:10.1177/0192636510379901 